\title{
Psychiatry and the movies: Men in Black
}

\author{
Steven Naylor and Andrew Wilkinson
}

This family blockbuster film is about aliens given asylum on earth on condition they follow certain rules. Basically these are to live in a stated place, to allow access to the Men in Black and to remain in human disguise while in public places so as to not frighten the natives. The heroes are human secret agents who monitor the well-being of the aliens and ensure that they abide by their conditions of residence. Striking parallels with recent mental health developments are evident, particularly to at-risk registers and supervised discharge orders. This paper discusses these similarities and their possible consequences referring to events in the film to illustrate relevant points.

Recruitment and training of agents bares comparison with the medical profession. The gifted potential agent comes to the notice of the Men in Black organisation following the resourceful pursuit of a disguised alien engaged in petty crime. He is invited for an assessment where his attitudes and intellect impress the selection panel. When he then agrees to join the Men in Black he has little knowledge of quite what he is ultimately letting himself in for.

After basic training in the diagnosis and treatment of alien disorders the job starts. He is told he will soon become accustomed to 37-hour days, that his work is absolutely confidential, must not be discussed with anyone, and will require him ceasing contact with mainstream society for a time. Having been shown the basics by a capable and sympathetic senior agent he is left to his own devices to muddle through.

There are mishaps but the inspired newcomer emerges with flying colours ready for independent practice. In the film any mishaps are conveniently covered over by the agents erasing the relevant events from the minds of any involved humans. This is done using an infrared beam produced by an ophthalmoscope-like device. This has the advantages for the agents of minimising the likelihood of recrimination and litigation. It also benefits the public by preventing the development of post-traumatic stress disorder and avoiding the public outcry and panic that would result from awareness of aliens in our midst. The benefits for aliens from this obsessive secrecy is that they avoid suffering any backlash resulting from society's fear of them.

In the film the majority of the aliens are well integrated into society and indistinguishable from their 'normal' neighbours. The Men in Black monitor the aliens from secret but opulent headquarters, which is another world compared to the National Health Service facilities of a typical mental health trust.

There are, however, some similarities in that both share a plethora of computers, protocols and managers, with a relative lack of workers carrying out the duties of face-to-face contact with clients. As with our community mental health teams scarce resources must be directed at those with the most severe disorders. The Men in Black monitor the clients believed to be most at risk of disturbed behaviour and intervene when prodromal signs of problems developing become evident. In the film, as is feared with psychiatric patients, the aliens are prone to go underground and disappear at this stage before they receive their treatment.

The plot of the film is that an alien VIP is assassinated by an evil alien and an important icon for the VIP's race is stolen. The Men in Black are told they have hours to return the icon or the earth will be destroyed. The evil alien adopts a disguise which could be seen as stereotypical of someone with mental illness.

$\mathrm{He}$ is a clumsy figure with poor social skills and involuntary movements. The Men in Black are on his case brandishing the ray guns which they use for blasting non-compliant aliens into following the rules of residence. He proves surprisingly dangerous and resourceful but after much enjoyable action the Men in Black succeed in their task.

This could be a worrying forewarning of future community mental health care if diminishing resources are combined with stringent legally enforceable conditions and the major emphasis of a service is the administration of treatment with consent or otherwise. In the film the Men in Black operate with strictly enforced secrecy. This is obviously not the situation with the mentally ill who can be openly integrated in to society. We can only hope that sensational media coverage of 
inevitable and tragic incidents does not lead to increased stigmatisation and the public refusing to have mentally ill people in their midst.

The film finishes with the senior agent retiring as soon as he thinks his junior is sufficiently experienced to take over so that he can resume a normal family life. This suggests a further similarity with the increasing burn-out and early retirement of the medical profession. Overall, we found Men in Black to be an enjoyable film and suitable for a family audience. It is likely that the parallels with mental health care are too subtle to overtly influence the viewers but at a less conscious level they may fuel prejudice against people with mental health problems.

*Steven Naylor, Senior House Officer, and Andrew Wilkinson, Consultant in Psychiatry of Old Age, Carn Brea Eldercare Centre, West End, Redruth TR15 2SF

*Correspondence

\section{Using the Mental Health Act}

\section{A Training Resource for Doctors}

\section{Prepared by the Royal College of Psychiatrists' Working Group}

This training pack is intended to support the development of better training for psychiatrists seeking approval under Section 12 of the Mental Health Act (1983) and to support the continuing education of psychiatrists and GPs. It comprises a 45 minute video, comprehensive written guidelines and lecture notes, together with overhead projector masters. It is intended as an aid (a) to those running training seminars within hospitals or trusts and others wishing to set up their own seminars, and (b) to individual practitioners who work in more isolated settings and who may wish to use distance learning. Published 1997, ISBN 190124209 9, 93 page text +18 unbound presentation masters, 1 PAL video cassette 45 min length. Video cassette and text held together in a white $P V C$ ring binder: Price $£ 45.00+$ VAT.

Available from Booksales, Publications Department, Royal College of Psychiatrists, 17 Belgrave Square, London SW1X 8PG (Tel. +44(0)171 235 2351, extension 146). The latest information on College publications is available on the INTERNET at: www.rcpsych.ac.uk 